\title{
Shear-lag effect and its effect on the design of high-rise buildings
}

\author{
Bui Thanh Dat ${ }^{1 *}$, Alexander Traykov ${ }^{2}$, Marina Traykova ${ }^{3}$ \\ ${ }^{1}$ National University of Civil Engineering, Hanoi, Vietnam \\ ${ }^{2}$ University of Architecture, Civil Engineering and Geodesy, Sofia, Bulgaria \\ ${ }^{3}$ University of Architecture, Civil Engineering and Geodesy, Sofia, Bulgaria
}

\begin{abstract}
For super high-rise buildings, the analysis and selection of suitable structural solutions are very important. The structure has not only to carry the gravity loads (self-weight, live load, etc.), but also to resist lateral loads (wind and earthquake loads). As the buildings become taller, the demand on different structural systems dramatically increases. The article considers the division of the structural systems of tall buildings into two main categories - interior structures for which the major part of the lateral load resisting system is located within the interior of the building, and exterior structures for which the major part of the lateral load resisting system is located at the building perimeter. The basic types of each of the main structural categories are described. In particular, the framed tube structures, which belong to the second main category of exterior structures, seem to be very efficient. That type of structure system allows tall buildings resist the lateral loads. However, those tube systems are affected by shear lag effect - a nonlinear distribution of stresses across the sides of the section, which is commonly found in box girders under lateral loads. Based on a numerical example, some general conclusions for the influence of the shearlag effect on frequencies, periods, distribution and variation of the magnitude of the internal forces in the structure are presented.
\end{abstract}

\section{Introduction}

\subsection{History of tall buildings}

In the late nineteenth century, tall buildings emerged in the United States of America. Most important tall buildings were built in the USA. An official 10-story (and, after an 1890 addition, 12) tall building called Home Insurance Building located in Chicago (1885) with $55 \mathrm{~m}$ high is considered the world's first skyscraper [1], as shown in Figure 1.

Based on various complex factors, such as economics, aesthetics, technology, municipal regulations and politics, tall buildings also appear and rapidly increase in number in other parts of the world, especially in Asian countries, such as China, Indonesia, Japan, and United Arab Emirate. As the height of tall buildings increased and record was constantly broken, tall buildings have become a symbol of prominence. According to a data published in 2017 [2],

\footnotetext{
${ }^{*}$ Corresponding author: thanhdat55xe@gmail.com
} 
there are more than a hundred of tall buildings above $300 \mathrm{~m}$ constructed in the world. Burj Khalifa (Dubai-2010) is presently the tallest building in the world, with 163 stories and 829.8 $\mathrm{m}$ high. By 2020, this record is expected to be broken by the appearance of Jeddah Tower-a 167 -story $(1000 \mathrm{~m})$ building- which is under construction in Jeddah city.

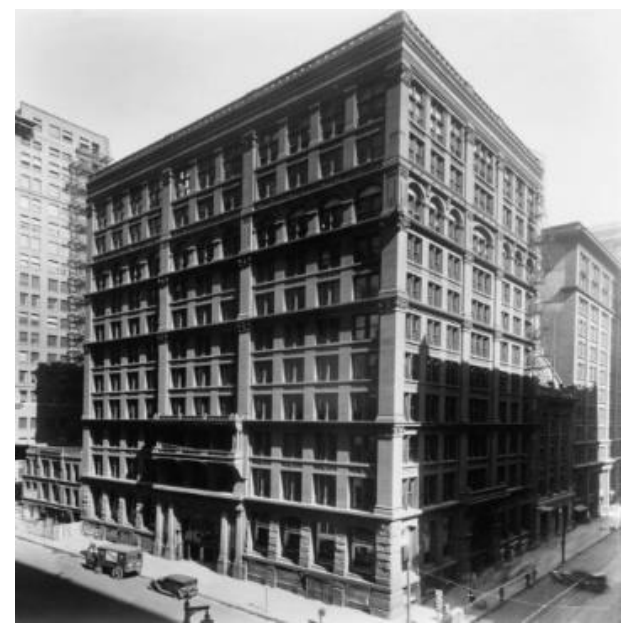

Fig. 1. Home Insurance Building - Chicago [1]

Table 1. Total number of completed tall buildings in countries (2017) [2]

\begin{tabular}{|l|l|l|l|l|}
\hline Country & All buildings & $100 \mathrm{~m}+$ & $200 \mathrm{~m}+$ & $300 \mathrm{~m}+$ \\
\hline United States & 4,664 & 2,517 & 180 & 17 \\
\hline China & 2,629 & 1,899 & 503 & 49 \\
\hline Canada & 1,052 & 472 & 21 & 0 \\
\hline Australia & 930 & 349 & 31 & 1 \\
\hline Russia & 797 & 218 & 16 & 5 \\
\hline Indonesia & 597 & 154 & 31 & 0 \\
\hline Japan & 556 & 467 & 37 & 1 \\
\hline Brazil & 532 & 176 & 1 & 0 \\
\hline United Arab Emirates & 413 & 283 & 91 & 23 \\
\hline United Kingdom & 368 & 66 & 5 & 1 \\
\hline
\end{tabular}

\subsection{Structural systems of tall buildings}

A tall building is assumed as a beam cantilevering from the earth which is subjected to axial loading by gravity and to transverse loading by wind or earthquake as shown in Figure 2. As the building becomes taller, the total gravity loads increase dramatically and the building sway due to lateral loads becomes critical. The gravity loads act on floors which transfer them horizontally to the vertical walls and columns through which they are transmitted to the foundation. The magnitude of axial loading can be estimated from the slab areas, so its calculation is not usually considered to be a difficult problem. On the other hand, the response of a structure to horizontal loads is more complex because it has to carry the external shear, moment, and torque [3].

In resisting shear forces, the building must not break by shearing off and not strain beyond the limit of elastic recovery. Regarding the bending resistance, the building must not overturn from combined forces of gravity and lateral loads; it must not break by premature failure of columns; its bending deflection should not exceed the limit of elastic recovery. Torsion on a 
building is resisted mainly by shear in the vertical components, by the horizontal components of axial force in any diagonal bracing members, and by shear and warping torque resistance of elevator, stair, and service shafts.

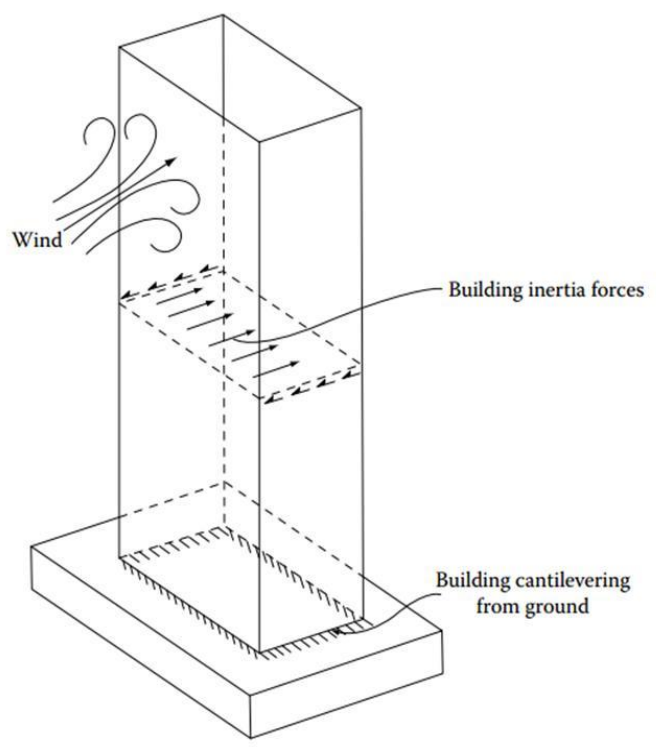

Fig. 2. Structural concept of tall building.

As discussed in a thematic report [4], structural systems of tall buildings can be classified by two main groups:

- Group of basic systems: Frame, Shear wall, Core, and tube

- Group of mixed systems: combination of two or more basic systems.

In the recent development, unlike the above classification, a system-based board classification has been proposed. In 2007, Mir M. Ali and Kyoung Sun Moon [5] divided structural system of tall buildings into two board categories:

- Interior structures: the major part of the lateral load resisting system is located within the interior of the building.

- Exterior structures: the major part of the lateral load resisting system is located at the building perimeter.

This new classification is presented based on the importance of height for tall buildings and the lateral load resisting capabilities. Therefore, it encompasses most representative tall building structural systems used today.

The category of interior structures consists of three basic types:

- The moment - resisting frames consist of horizontal (beam) and vertical (column) members rigidly connected together in a planar grid form. This system resists lateral deformation by joint rotation and requires high bending stiffness of columns and beams. The rigid joints are also essential for stability. However, this system is not efficient for buildings over 30 stories in height because the shear racking component of deflection caused by the bending of columns and beams causes the building to sway excessively.

- Shear truss/shear wall - frame interaction systems are a combination of rigid frames and reinforced concrete shear walls. This system seems to be more efficient than frame system in terms of lateral resistant for buildings up to 70 stories. The lateral rigidity of tall buildings could be increased by the combination of the approximately linear shear-typed deflected profile of frame system and the parabolic cantilever sway mode of shear wall. 
- Outrigger structures have been historically used by sailing ships to help resist the wind forces in their sails, making the tall and slender masts stable and strong. In tall buildings where the core is considered as pure cantilever, the outriggers can reduce overturning moment in the core and transfer its reduction to the outer columns. The outrigger systems may be formed in any combination of steel, concrete and composite construction.

The category of exterior structures consists of following basic types:

- Framed tube is a basic tubular form which consists of closely spaced columns and deep spandrel beams rigidly connected together throughout the exterior frames. This type is reasonably efficient from 38 to $300 \mathrm{~m}$ in height.

- Braced tube is a variation of the framed tube. By using diagonal braces to connect columns at each joint, the columns can be more widely spaced and the sizes of spandrels and columns are smaller than those in framed tube. The braces also transfer gravity loads as inclined columns.

- Bundle tube is a combination of individual tubes. Those connected tubes act as a single unit where the three dimensional response of the structure could be improved for strength and stiffness by providing cross walls or cross frames in the building.

- Another tubular system is tube-in-tube. One or more tubes are located inside the perimeter tube. The floor diaphragm transfers lateral loads by connecting the core and the outer tube.

- Besides tubular form, diagrid system is also a type of exterior structures. It consists of multiple diagonal elements that form a diagonal grid on the face of the structure. The grid system makes the structure stable even without having any vertical columns. This is because the diagonal members in diagrid structural system can carry gravity loads as well as lateral forces due to their triangulated configuration.

- Super-frame is another type of lateral load resisting systems in exterior structures. This system is composed of mega-columns comprising braced frames of large dimensions at building corners, linked by multistory trusses at about every 15 to 20 stories.

The framed tube structures, which belong to the second main category of exterior structures, seem to be very efficient. That type of structural system allows tall buildings resist the lateral loads. Basically, the system consists of perimeter closely space columns connected at each floor with deep spandrel girders, thereby creating the effect of a hollow concrete tube. Framed tube structure allows fewer interior columns, and so creates more usable floor space. The system acts like a hollow cylinder, cantilevered perpendicular to the ground. However, these tube systems are affected by shear lag - a nonlinear distribution of stresses across the sides of the section, which is commonly found in box girder under lateral loads.

\section{Materials and methods}

\subsection{Introduction to shear lag}

Shear lag effect has been studied for a long time, with the observation in box girder and any hollow structure which are subjected to lateral load. According to the elementary theory of bending states (Euler-Bernoulli beam theory), a plane section remains plane before and after bending. As a result, the variation of bending stress in the cross section along flange and web panels must be varying linear. In fact, the real distribution of these axial stresses is observed not linear. Due to the shear flow developing in the section, the panels displace longitudinally in the way that the middle portion of the flange and web lag behind that of the portion closer to the corner of the box section, as discussed by Leonard [6]. 


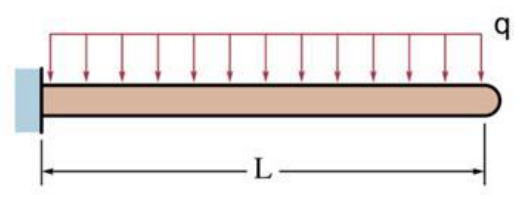

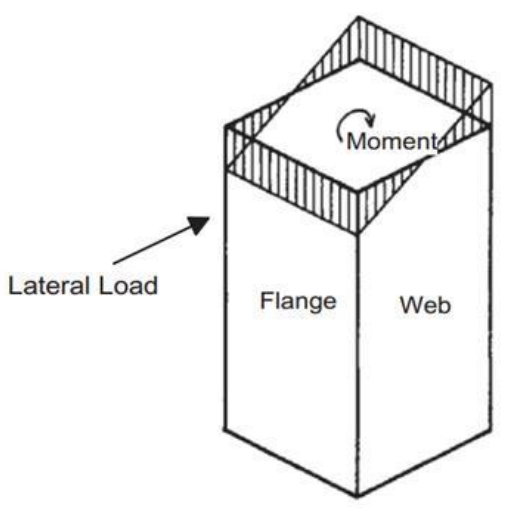

(a) with no shear lag

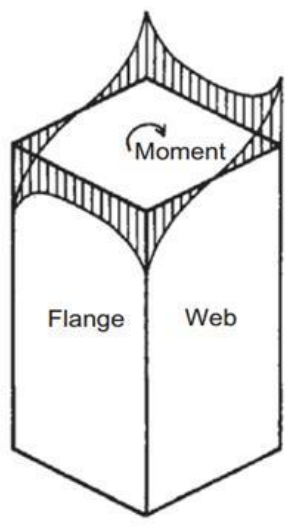

(b) with shear lag - positive

Fig. 3. Axial stress distribution in box cantilever beam [6]

Shear lag has been of interest to researchers for a long time. Shear lag in box girder was first studied by Eric Reisser in 1941. He gave applications of the fundamental equation to the actual solution of a series of shear lag problems [7]. Different aspects of the issue are considered in those researches listed in references [7-10].

\subsection{Shear lag in framed tube structures}

Generally, the lateral load resistance of framed tube system is highly promoted with the help of tube action. When subjected to lateral load, the tube behaves like a cantilever box beam, where the column deflects in lateral direction and beam deflects in bending. During the tube action, the shear lag occurs. This type of tubular structure also shows the real distribution of axial stresses against with the elementary theory of bending, in that the axial stresses applied in the columns of the peripheral flange are non-uniform and the stress distribution in the web panel are nonlinear. In framed tube systems, two different modes of shear lag may occur: negative shear lag and positive shear lag. As shown in Figure 4, positive shear lag in tube structures show the higher axial stress in the corner columns than that of middle columns [11]. This results in the warping of the floor slabs which leads to the consequent deflection of the secondary components. 


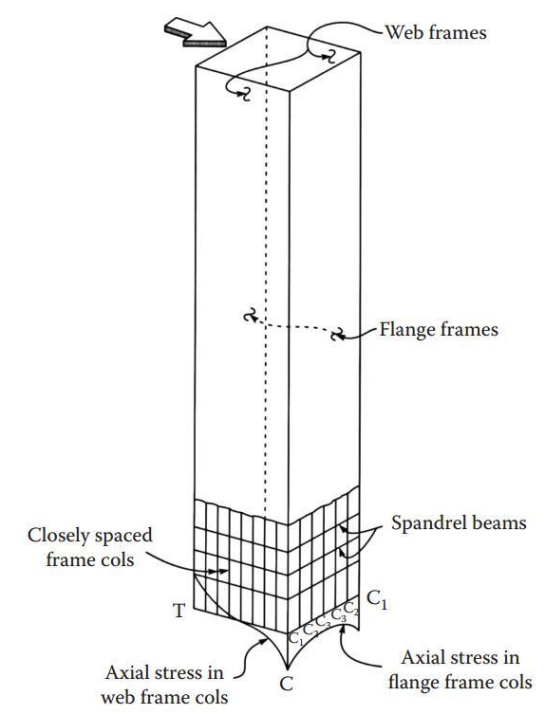

Fig. 4. Axial stress distribution in the column of framed tube building [11].

Many researchers studied shear lag effects in framed tube structures. In 1961, framed tube structural system was introduced by Fazlur Khan as one kind of exterior structures. The structure system of framed tube building was analyzed by using equivalent plane frame elements method. These studies were carried out by Coull and Ahmed (1978), Ha et al. (1978). In 1994, Kwan proposed more realistic assumption that the distribution of axial displacement of the web is independent of its in flange panel. Kwan found that shear lag is also influenced by the loads on structure and this effect at the bottom of the structure is usually higher than at the upper levels, as discussed by Leonard [6]. Y. Singh and A. K. Nagpal (1994) investigated in negative shear lag by modeling a 40-storey framed tube building. They found that positive shear lag occurs in the bottom part of the building while negative shear lag occurs at the top part, as shown in Figure 5. Shear lag effect is more significant for buildings with low ratio between the number of stories and the number of bays. They concluded that the origin of negative shear lag is positive shear lag. It is also observed that the corner columns may experience axial stresses opposite to those in the middle columns [12]. In 2000, Kang-Kun Lee, Hong Guan, and Yew-Chaye Loo used numerical method to analyze shear lag effect in framed tube structures with multiple internal tubes, as shown in figure 2-9. By investigating through a series of 40 -storey buildings, they observed that the shear lag reversal points move towards the top of the structure with the increasing of shear lag and take place at a lower level in internal tubes than those in external tube [13]. Lee at el. (2002) extended a parametric study to examine the shear lag behavior of single and multiple framed tube buildings. He reported that "the axial stiffness of the columns was the most influential factor on the tube action as well as shear lag behavior, while the bending stiffness of columns and beams were a little impact perhaps due to the tube-in-tube interaction" [14]. In 2005, Kyoung Sun Moon [15] and Johan Leonard [6] discussed the behavior of diagrid system. Moon found that the optimal angle varies between $53^{\circ}$ and $76^{\circ}$ and this optimal angle reduces as the number of story decreases. He also found that the optimal value of "s", which is the ratio between the displacement at the top of the structure due to bending and the displacement due to shear, would be 3,4, and 5. Leonard concluded that the optimal angle for diagrid system varies between 63.4 degree and 71.6 degree, and shear lag effect does not influence the lateral deflection of high-rise buildings. 


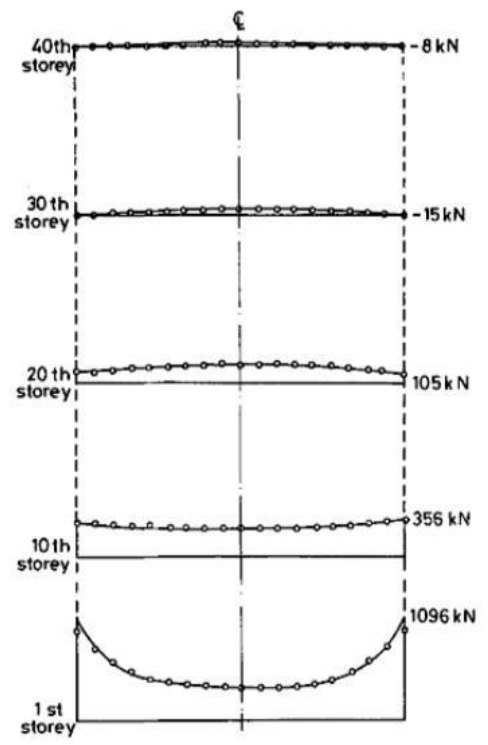

Fig. 5. Axial forces in flange - studied by Singh and Nagpal [12]

More recent studies about shear lag effect in tube structures have been conducted. In 2013, Farshid Nouri and Payam Ashtari studied shear lag in braced tube tall structures compared to framed tube tall structures as a solution to resist shear lag phenomenon. They analyzed number of factors affecting to shear lag ratio and concluded that edge columns stiffness, spandrel beam stiffness and diagrid angle are factors which play important roles on reducing shear lag phenomenon. They also recommended that it is needed to investigate separately the behavior of concrete and steel structures [16]. In 2014, D. Nagvekar and P. Hampali carried out their study on hollow structure by using Etabs software to analyze a 30story tubular framed building. From the study, they noted that negative shear lag gets the maximum at top and occurs only after positive shear lag has occurred [17]. In 2015, Himanshu Gaur and Ravindra K. Goliya [18] conducted a study of a tube-in-tube structural system with facade bracing as a solution to mitigate shear lag. A number of different types of buildings were modeled in SAP 2000. It is found that for the heights between 120 and 48 stories, the bracing angle fluctuating between $63.43^{\circ}$ and $45^{\circ}$ show the least lateral deflection. Other approaches of reducing shear lag are providing additional structure, such as mage bracings or belt trusses. Those structures can be used to increase the shear stiffness of the flange and web frames of the framed tube building $[19,20]$.

Shear lag effect is an unexpected major phenomenon that controls the design of tall buildings using framed tube system. There are many researches with different analysis methods have been conducted to study the effect of shear lag not only in box girder, but also in tube structures. However, most of the previous studies focused on box girder, tube structures with exterior bracing system, and tube-in-tube structures. Not many studies have been attempted to describe shear lag effect and its variation along a framed tube structure.

The paper is dedicated to the modelling and the analysis of high-rise concrete building using framed tube structure with varying parameters, using ETABs software. Under the action of lateral loads, it is proposed to study the understanding of shear lag phenomenon in framed tube structure. The variables are considered in terms of building cross section and the spacing between outer columns.

\subsection{Structural modeling}


A 60-story framed tube concrete building with $3 \mathrm{~m}$ high of each story is modeled in ETABs 2015: size of columns $1 \times 1 \mathrm{~m} 2$, size of beam $0.5 \times 1 \mathrm{~m} 2$, slab thickness $0.25 \mathrm{~m}$. There are four models with different parameters as follows:

Table 2: Different models of building

\begin{tabular}{|c|c|c|c|c|}
\hline Parameter & Model 1 & Model 2 & Model 3 & Model 4 \\
\hline Cross section & $\begin{array}{c}\text { Square } \\
24 \times 24 \mathrm{~m}^{2}\end{array}$ & $\begin{array}{c}\text { Square } \\
24 \times 24 \mathrm{~m}^{2}\end{array}$ & $\begin{array}{c}\text { Rectangular } \\
18 \times 36 \mathrm{~m}^{2}\end{array}$ & $\begin{array}{c}\text { Rectangular } \\
18 \times 36 \mathrm{~m}^{2}\end{array}$ \\
\hline Column spacing & $3 \mathrm{~m}$ & $6 \mathrm{~m}$ & $3 \mathrm{~m}$ & $6 \mathrm{~m}$ \\
\hline
\end{tabular}

The building is subjected to both gravity loads and lateral load. The gravity loads are estimated as in a real office building: dead load is $4 \mathrm{kN} / \mathrm{m}^{2}$ and live load is $3 \mathrm{kN} / \mathrm{m}^{2}$. The earthquake load is applied according to Eurocode-8 (2004) [21], soil type C in Sofia Bulgaria. Cross-sections of different models are presented in Figure 6.

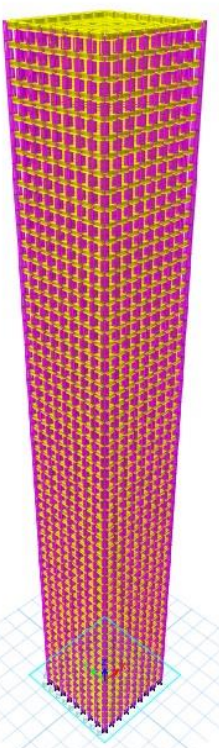

3D-view

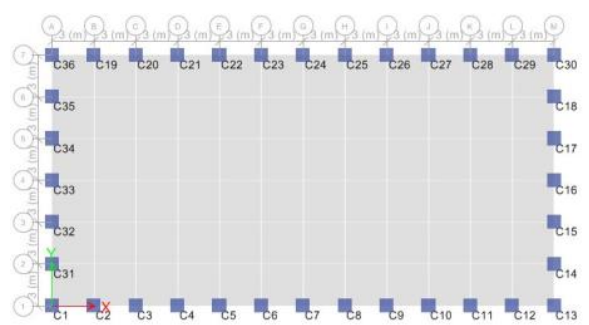

c) Model 3

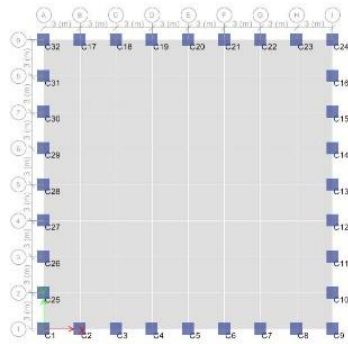

a) Model 1

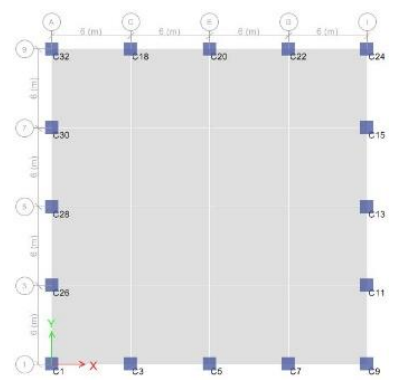

b) Model 2

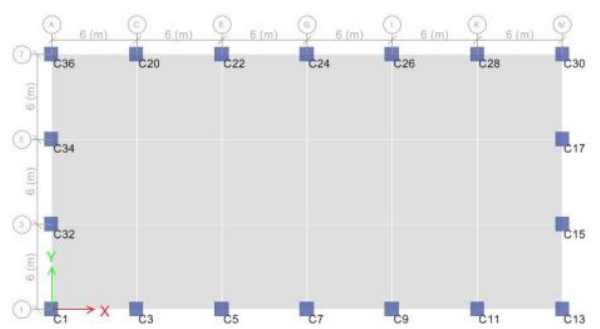

d) Model 4

Fig. 6. Cross section of different building models 


\subsection{Main assumptions for analysis}

The modeling and analysis approach used for parametric study are summarized as follows:

- The floor slabs in the structure are considered to be rigid diaphragms within their own plane. Thus, the high in-plane stiffness of the slabs restricts the relative lateral displacements between columns at each level.

- Joints between the spandrel beams and columns are assumed rigid.

- The building is supported by fixed supports.

- The spacing, materials, and size of the beams and columns are uniform throughout the building height.

\section{Results}

The following main results are obtained from the numerical modeling.

The results are presented as shear lag ratio - a non-dimensional parameter. Shear lag ratio is defined as the ratio of axial force in each column to axial force of the middle column in the same axis. In this section, the influences of building cross section and column spacing on shear lag effect are investigated.
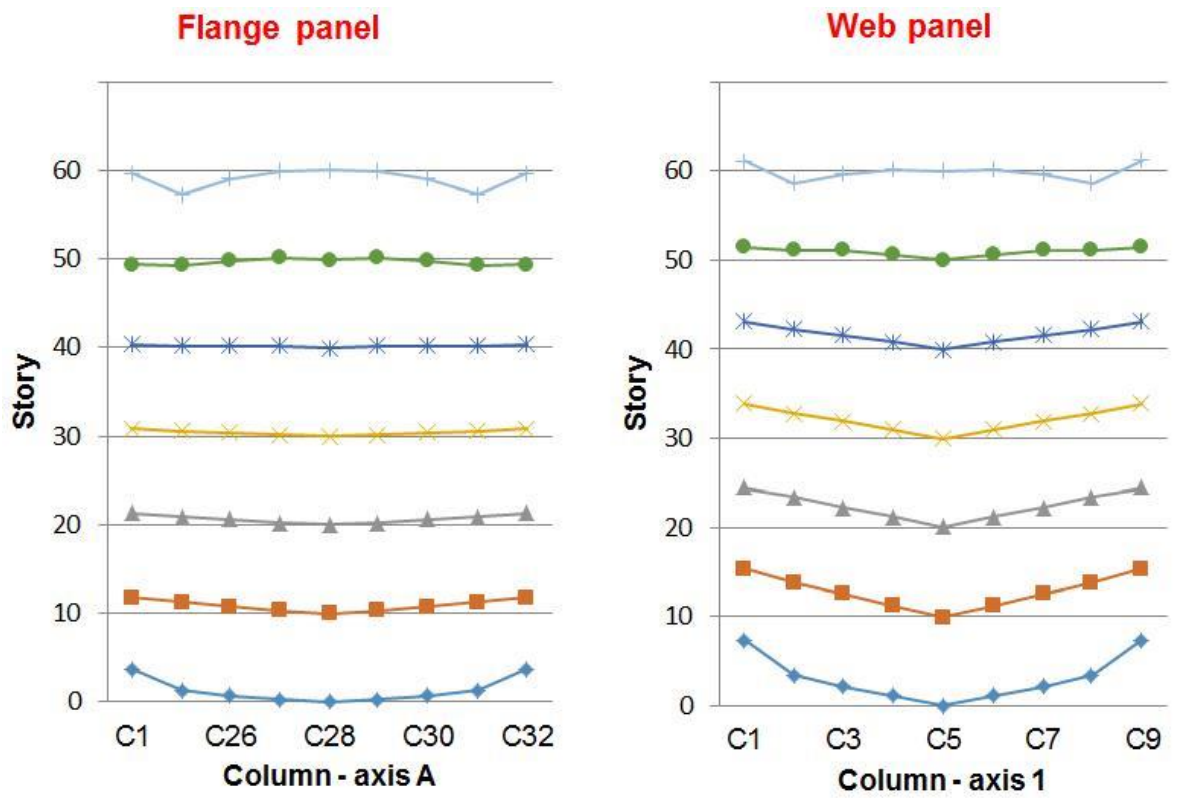

Fig. 7. Shear lag ratio distribution flange and web columns - model 1. 

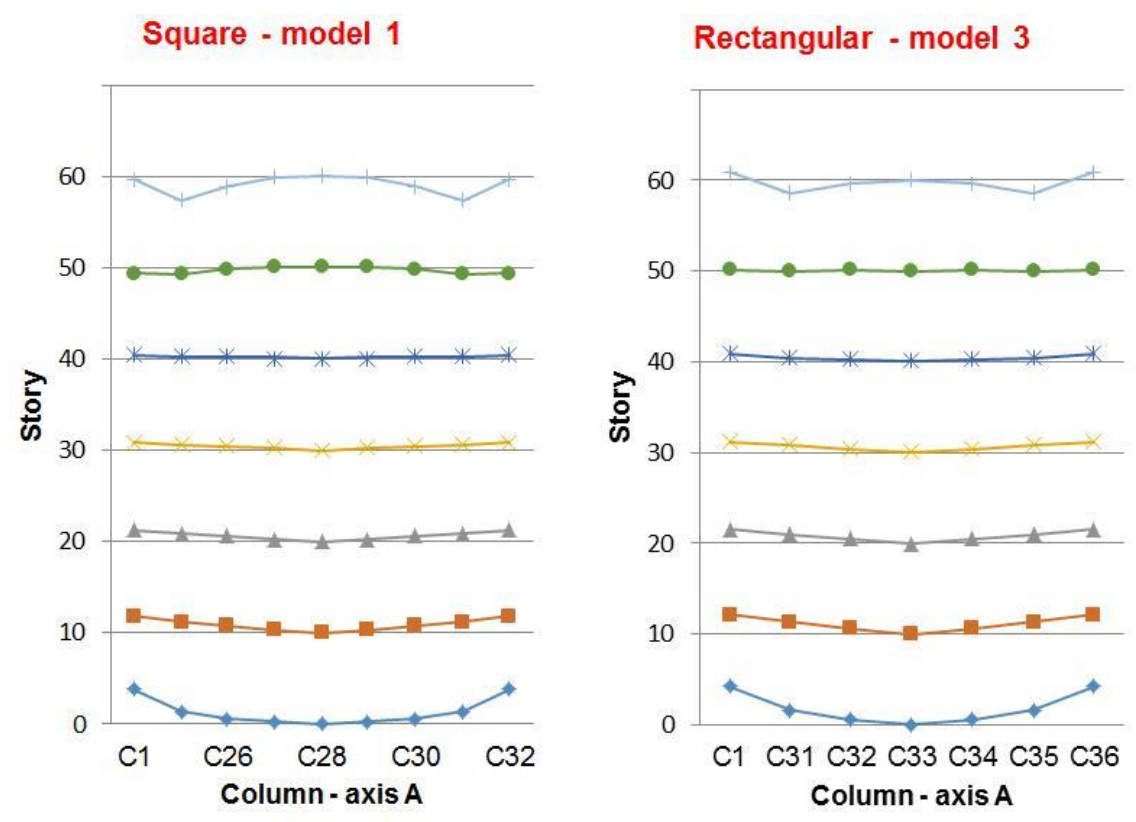

Fig. 8. Shear lag ratios distribution in building with different cross section shapes.
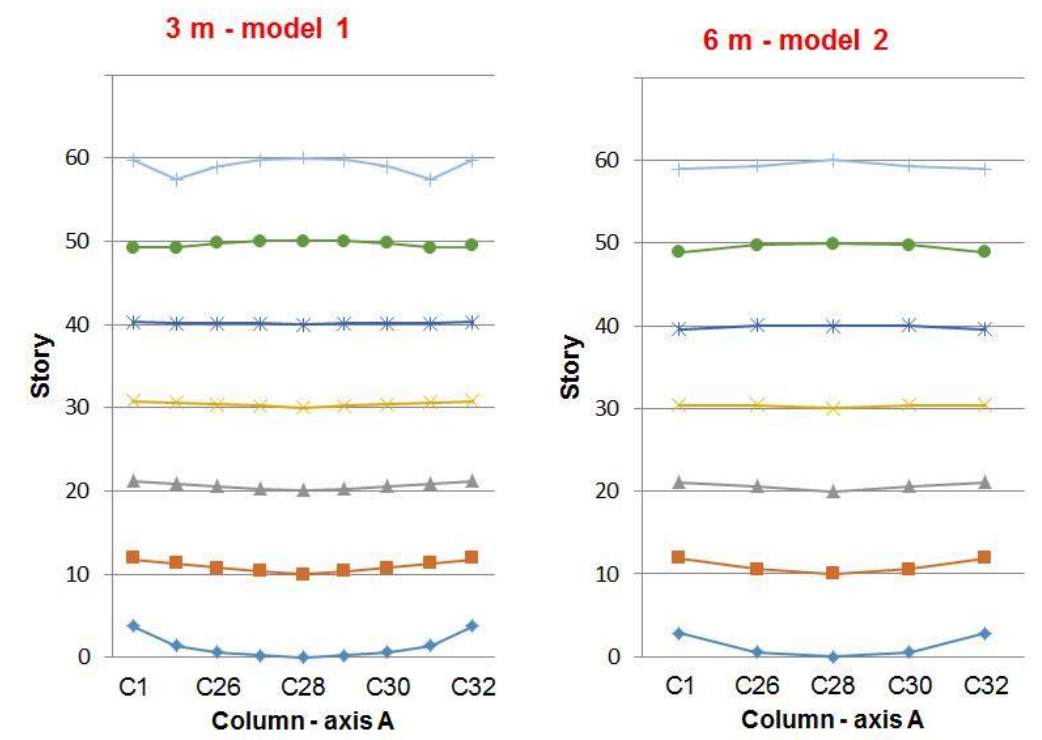

Fig. 9. Shear lag ratios distribution in square buildings with different column spaces. 

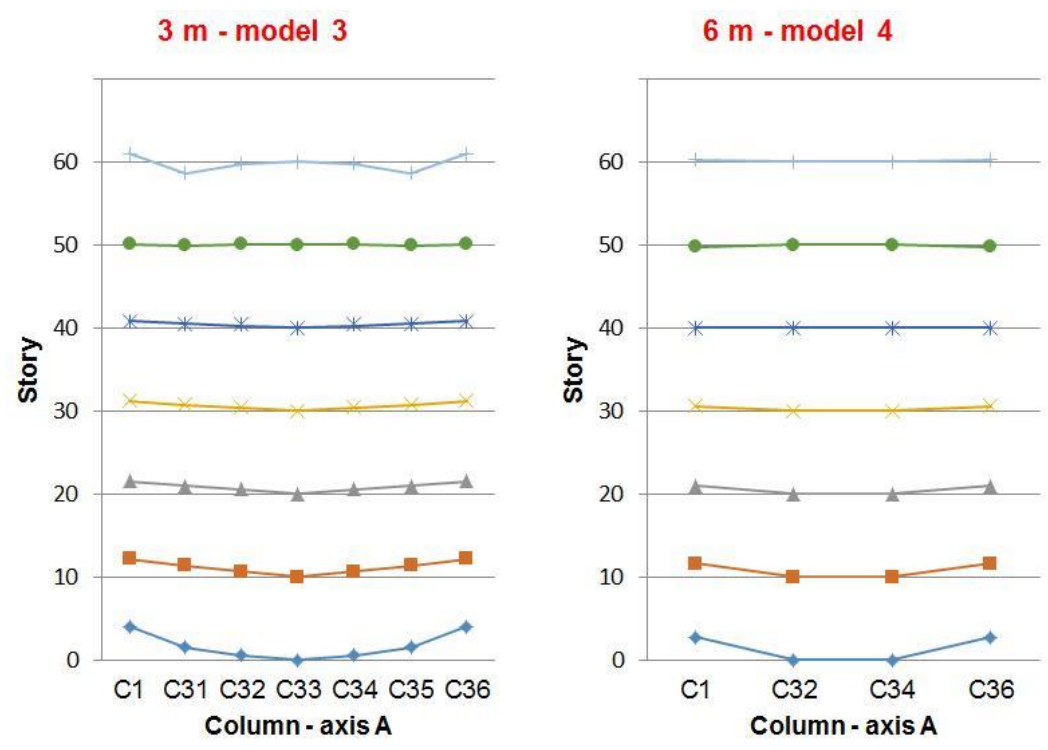

Fig. 10. Shear lag ratios distribution in rectangular buildings with different column spaces.

The description of the different models is presented in the previous section.

\section{Discussion}

All the results for the axial forces correspond to load combinations of vertical and horizontal loads rather than lateral loading only. That is the reason for the differences between the presented results for the axial forces in the web panels in this article and in other researches.

In Figure 7, shear lag effect can be observed in a 60 -story framed tube building (model 1). The positive shear lag can be seen in the bottom part of the building, while the top part shows negative shear lag. The value of positive shear lag ratio is highest at the ground story. It decreases till it becomes zero as the increase of height, at around 40th story, then it transfers to negative shear lag. The negative shear lag ratio, on the other hand, increases from 40th story to the top of the building. The same trends are founded in the other models.

\subsection{Building cross section variation}

Two models with square (model 1) and rectangular cross section (model 3) are analyzed. The results of shear lag ratio in flange panel can be seen in Figure 8.

In the square section building, positive shear lag is inverted to negative shear lag at around 40th story, whereas it is changed at nearly 50th story in rectangular section building.

\subsection{Column spacing variation}

This section compares shear lag effect in buildings with the changing pattern of space between outer columns, from $3 \mathrm{~m}$ (model 1 and model 3 ) to $6 \mathrm{~m}$ (model 2 and model 4 ).

Figure 9 and Figure 10 show that the shear lag ratio in $6 \mathrm{~m}$-spacing buildings are smaller than those in $3 \mathrm{~m}$-spacing buildings. The difference can be seen clearly in the top part of the building where the negative shear lag occurs. 


\section{Conclusions}

Based on the presented in the paper analysis, the following conclusions could be done:

- Shear- lag effect is a phenomenon typical for the framed tube structures under horizontal loads.

- The presented study shows the existence of both positive and negative shear-lag effect in the framed tube structures of the considered type.

- The positive shear-lag effect decreases with the floor levels and then it transfers to negative shear-lag effect which increases up to the top of the building.

- The shear-lag effect is not significantly influenced by the ratio of the building's dimensions in plan.

- The shear lag effect decreases when the column spacing increases. The column spacing affects the negative shear-lag effect more clearly at the top half of the building.

The present paper studies the shear-lag effect in a framed tube structure where some specific building features are not modeled. Future research shall consider the influence of the internal walls around stairs and elevators, as well as the effects of taking into account of the construction sequence.

\section{References}

1. http://www.theguardian.com. (last accessed 04.04.2017)

2. http://www.skyscrapercenter.com. (last accessed 08.04.2017)

3. B. S. Taranath, Steel, concrete, and composite design of tall buildings (New York: McGraw-Hill, 1997)

4. Thematic report: "Đề xuất lựa chọn hệ kết cấu BTCT chịu tải trọng ngang cho nhà siêu cao tầng ở Việt Nam (Solution for lateral resisting systems of reinforced concrete highrise buildings in Vietnam)". Division of Reinforced Concrete Buildings (National University of Civil Engineering (NUCE), Vietnam, 2015)

5. M. M. Ali, K. S. Moon, Structural Developments in Tall Buildings: Current Trends and Future Prospects, Architectural Science Review, 50(3), 205-223 (2007)

6. J. Leonard, Investigation of Shear Lag Effect in High-rise Buildings with Diagrid System, Master's thesis of Engineering, (Massachusetts Institute of Technology, 2007)

7. M. H. M. Al-Sherrawi, G. A. Fadhil, Effect of stiffeners on shear lag in steel box girders, Al-Khwarizmi Engineering Journal, 8(2), 63-76 (2012)

8. V. Kristek, Z. P. Bazant, Shear lag effect and uncertainty in concrete box girder creep, Journal of Structural Engineering, 113(3) (1987)

9. Y. Zhou, Analysis of the shear lag effect of cantilever box girder, Engineering Review, 34(3), 197-207 (2014)

10. R. K. Sorensen, Evaluation of shear lag in standard H-/I-sections, (Aalborg University Esbjerg, 2013)

11. B. S. Taranath, Structural analysis and design of tall buildings: Steel and composite construction (New York: McGraw-Hill, 1988)

12. Y. Singh, A. K. Nagpal, Negative shear lag in framed-tube buildings, Journal of Structural Engineering, 120(11) (1994)

13. K.-K. Lee, H. Guan, and Y.-Ch. Loo, Simplified analysis of shear lag in framed tube structures with multiple internal tubes, Computational Mechanics, 26(5), 447-458 (2000) 
14. H. A. Ghasemi, Optimal design of high-rise building bundled tube systems, Advances in Science and Technology Research Journal, 10(30) (2016)

15. K. S. Moon, Dynamic relationship between technology and architecture in tall buildings, PhD thesis, (Massachusetts Institute of Technology, 2005)

16. F. Nouri, P. Ashtari, Investigation of the shear lag phenomenon and structural behavior of framed tube and braced tube tall structures, Int. Conf. on Civil Engineering, Architecture \& Urban Sustainable Development (Tabriz, Iran, 2013)

17. Y. D. Nagvekar, M. P. Hampali, Analysis of shear lag effect in hollow structure, International Journal of Engineering Research \& Technology (IJERT), 3(7) (2014)

18. H. Gaur, R. K. Goliya, Mitigating shear lag in tall buildings, Int. Journal of Advanced Structural Engineering (IJASE), 7(3), 269-279 (2015)

19. J. C. D. Hoenderkamp, H. H. Snijder, Preliminary analysis of high-rise braced frames with façade riggers, Journal of Structural Engineerinf, 129(5) (2003)

20. R. S. Nair, Belt trusses and basements as "virtual" outriggers for tall buildings, Engineering Journal, AISC, 35(4) (1998)

21. Eurocode-8, Design of structures for earthquake resistance (2004) 